\title{
Communication critical incidents: how to improve human factor?
}

Authors: Hernández I, Gago S, Lema M, Palencia M, Garrido A, Romera A.

\section{SSSENSAR}

Sistema Español de Notificación

en Seguridad en Anestesia y Reanimación
SAM

SaludMadrid
Hospital Universitario Gregorio Marañón

Has Comunidad de Madrid

\section{Background}

Half of the critical incidents $(\mathrm{Cl})$ at hospital

environment occur in the operating room. The main contributory factor involved is the so-called "human factor". This term refers to both the non-technical skills that each one has as well as teamwork. The main non-technical skills are communication, coordination, shared mental model and leadership skills. Of these, communication capacity is essential because it connects the other elements.
The aim of the study is to review

the national base of the $\mathrm{Cl}$ reported ("SENSAR database") to analyze those in which communication is a contributing factor.

\section{Materials and methods}

- Retrospective observational study.

- $\quad 6205 \mathrm{Cl}$ reported in SENSAR database, which is called "Anestic".

- January $2009 \rightarrow$ October 2016.

- Identifying those in which the communication error appears as a contributing factor.

\section{Results and discussion}

$6205 \mathrm{Cl} \rightarrow 1957$ (32\%) in which some communication error influenced the production of $\mathrm{Cl}$

\section{CONTRIBUTING FACTORS}

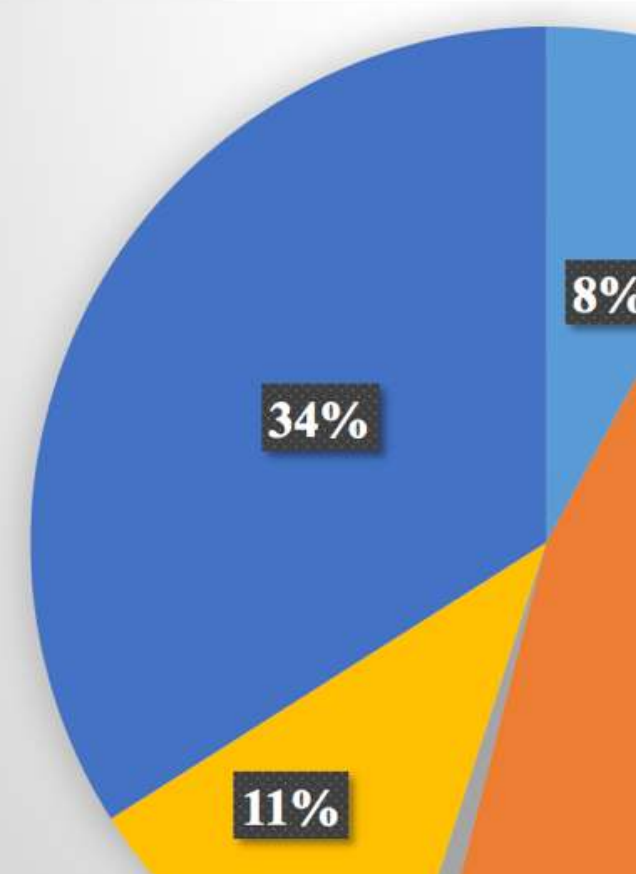

$1 \%$
Communication error between doctor and patient

Communication error between doctor and other staff

Delay or denial in looking for help

Absence of close supervision

- Communication error between doctors

\section{MORBIDITY}

- $2 \%$ Major morbidity

- $4 \%$ Intermediate morbidity

- $8 \%$ Not harm but suspension surgery

- $73 \%$ no harm

\section{Cases $\rightarrow$ deaths}

\section{Improvement measures:}

* Sending alerts in bulletins- vía email

* Simulation

*Online courses in "CRM"

* Online courses in Helsinki declaration

\section{Conclusions}

In other international series, human factor is the main one involved in $\mathrm{Cl}$ development. Effective communication in a team is an essential aspect of it. The standardization of information transmission, simulation, Crisis Resource Management courses and debriefing are some of our tools available to enhance non-technical skills. 